\title{
The Situation of the Elderly in Bangladesh
}

\author{
Antoni Barikdar ${ }^{1}$, Tahera Ahmed ${ }^{2}$, Shamima Parvin Lasker ${ }^{3}$ \\ 1. Project Manager-Health, World Vision Bangladesh, \\ 2. Former Acting Chief, SRHR, UNFPA, \\ 3. Professor and Head of Anatomy, MH Somrorita Medical Hospital \& College, Dhaka.
}

\begin{abstract}
In Bangladesh due to improved quality of life the number of people over 60 years is increasing rapidly. This should be seen as an emerging challenge as the elderly will have special needs and require different care-giving services. Since Bangladesh does not have a social welfare system there will be competition for inadequate resources specially health and medical services .It is envisaged that due to more elderly population the demographic structure will undergo a slow change from the present pyramid structure. The growing trend towards nuclear family or where children live abroad will put the elderly parents in a dilemma-the financial and social support that is essential for them has not yet emerged. The nutrition and health status of elderly people depend on adequate food safe water, proper sanitation facilities and maintaining hygienic standards. To provide special medical care for the elderly there is a need to establish WHO recommended Age-Friendly Primary Health Care centers and separate wards / units are to be set up in the hospitals. To reduce vulnerability of older women there is a need to distribute assets and properties according to the law. . Our new generations have to be responsive, informed and attentive about their duties and responsibilities towards the elderly people. Taking proper care of the elderly is our ethical duty and responsibility.
\end{abstract}

Key words: situation; elderly; ageing; Bangladesh

Introduction: A person mainly passes five stages in his lifespan. The stages are infancy, childhood, adolescence, adulthood and old age. Old age starts after sixty years of age and ends in death. Old age is one of the vulnerable situations in a natural process of life. In this stage, people experience decreased physical strength and deteriorating health conditions with age related disease. All over the world proportion of elderly are increasing where numbers of children are decreasing. According to World Population Ageing Report 2013, World's population 60+, 65+ and $80+$ were 840628, 570459 and 120199 respectively. Moreover this number were 468549, 307699 and 57576in Asia, 60033, 38513 and 5248in Africa, 169874, 125152 and 33239in Europe ${ }^{1}$. The statistical data of Bangladesh represent the number of aged population has increased from 1.38 million to 7.59 million from the year of $1974-2001^{2}$. Bangladesh is the seventh largest populated (152.51 million) and most densely (1015 person live per square kilometers) country ${ }^{3}$. Furthermore, the nuclear family is increasing in Bangladesh day by day and older people left alone living separately from their family and becoming vulnerable. This condition demands more health and welfare services and more provision to the elderly support system $^{4,5}$. 
There is not enough data about the situation of elderly people in Bangladesh. Therefore, this retrospective study was done on elderly population of Bangladesh to identify emerging issues and challenges of the elderly and to explore different type of vulnerabilities of elderly people in Bangladesh.

Methodology: This study focuses on vulnerability about elderly people of Bangladesh. For this, we have chosen different types of paper work and networking as well as some qualitative tools as research methodology. The major sources of information of this study were literature review. Literature review was done using different search engine e.g. Google scholar, online library PubMed between 1974 and2015. Key words were elderly, old people, aging, elderly, condition, Bangladesh, world. This study prepared as internship report for the fulfillment of the requirements of the Master of Public Health (MPH) Degree of North South University, Dhaka, Bangladesh.

Definition: Elderly people: Most people above 60 years of age are considered as 'old'. Those who are 60 years and above makeup the elderly section of any population ${ }^{6}$. Though this age limit also applies to Bangladesh,7, in reality people in this country become older earlier because of poverty, and the conditions related like hard labor, malnutrition, illness and their geographical condition $^{7}$.

Population ageing: Defined as an increase proportion of population, which is elderly ${ }^{7}$.

Social safety net: This is a network of services usually provided by the state which includes social services like old age benefits, healthcare, shelters, and subsidized services such as public transport, which prevent individuals from falling into poverty ${ }^{8}$.

Elderly people: context Bangladesh: Previously the society of Bangladesh took care of the elderly but now the situation is becoming changed due to change of social, psychological and economic standpoint. Social, economic and political viewpoint elderly population is now growing rapidly and it's a big concern for Bangladesh. According to the National census between 1974 and 2011 the growth of elderly people is gradually increasing. In 1974, the populations between 60-64 years were 1682629 and in 2011 the numbers were 3218974 . At the same way aged between 65-69 years population were 735255 and 1998760in 1974 and 2011 respectively. In the same period of time populations of elderly over 70 years were 1639056 to 1998760. Report shows that percentage of elderly people age between 60-64, 65-69, 70-75 and over 70 years were $37 \%, 21 \% 20 \%$ and $22 \%$ respectively. According the report of Bangladesh Bureau of Statistics the trends of elderly population increase gradually. Figure 1 shows the gradual increased percentage of elderly in Bangladesh. 


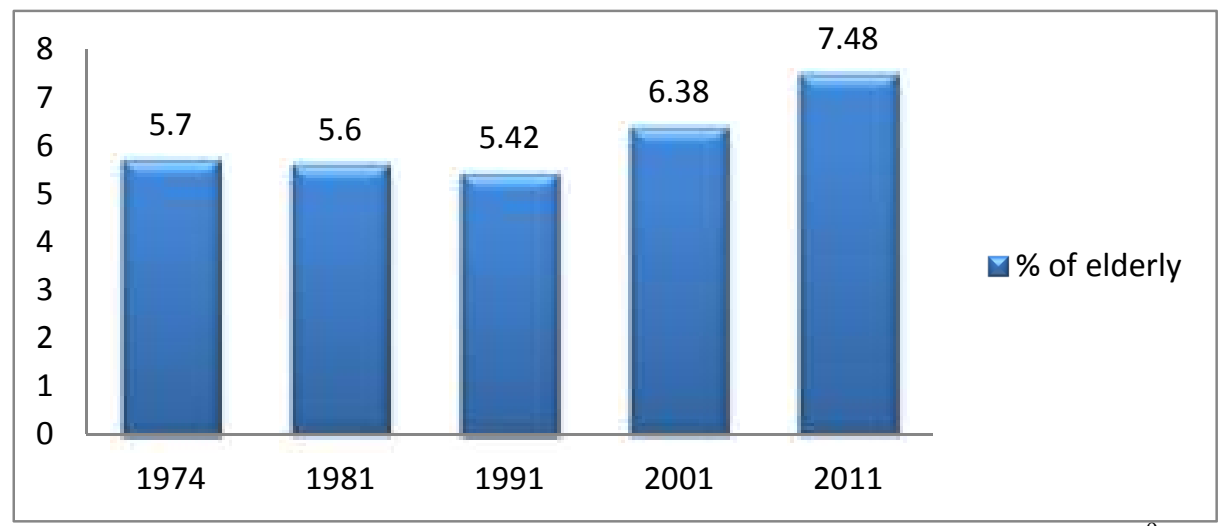

Figure 1: Trend in percentage of elderly population in Bangladesh ${ }^{9}$

A study report shows that in Bangladesh, majority of the people over 60 live in the rural areas where there is a lack of proper health care services, economic services and job opportunities are very limited. The situation of the elderly is dismal where more than $50 \%$ of the elderly are widowed or single $9.63 \%$ are jobless and $14-15 \%$ engaged in agricultural works and daily labor. This compares badly with that of Tehran where $85 \%$ elderly are unofficially employed ${ }^{10}$. Elder person encountered non-communicable diseases such as cardiovascular diseases including heart attacks and stroke, chronic respiratory diseases including chronic obstructed pulmonary disease and asthma, renal disease cancers, and diabetes as well as other chronic diseases ${ }^{11,12}$.

Moreover, research shows that children of older parents in Bangladesh live in cities for education, employment or living. Again, the older people fill comfortable to live in the rural settings and sometimes children are leaving their older parents to live in the city. ${ }^{13} 44.3 \%$ people live in poverty and in order to maintain their living expenses as well as family needs; the elderly people get involved in beggary ${ }^{14}$ However, older women especially widows and those who are without sons are facing economic vulnerability and consequence of health problem ${ }^{15,16}$.

Modern society has failed to keep the dignity and honor of the elders. This may be attributed to various reasons like individualistic attitudes, instability of family structures, devaluation of dignity, differences in incomes, and other social problems ${ }^{17}$. The same scenario is happening in Bangladesh.

Constitution of the Bangladesh mentioned the rights of elderly people. In the constitution part II section 15 entitled "Provision of Basic Necessities" described social security of the elderly people as the " provision of the basic necessities of life, including food, clothing, shelter, education and medical care; the right to reasonable rest, recreation and leisure; and the right to social security, that is to say, to public assistance in cases of undeserved want arising from unemployment, illness or disablement, or suffered by widows or orphans or in old age, or in other such cases mentioned in the 15 (a) (c) and (d) clause respectively ${ }^{18}$." 
Old age allowance introduce in Bangladesh in the Fiscal Year (FY)'1997-1998 and the main objectives of this allowance is ensuring socio-economic development and social security for the elderly; increase dignity of elderly within family and community. Aim of the allowance is to strengthening of mental health through grant for Medicare and increase of nutritional support for elderly people of Bangladesh. The age of 65 years for male and 62 years for female whose yearly average income not exceeding 10,000 BDT are considered eligible for the old age allowance. The total budget in FY'1997-1998 was 125.00 million BDT and monthly allocation for 100 taka per person and total beneficiary were 40,311. That amount of grant per head has been increased in the present FY' 2015-2016.Bangladesh government allocated BDT 14,400 million and the total beneficiary is 3 million, each beneficiary getting 400 BDT per head per month ${ }^{19}$.

However, Bangladesh has pension policies to ensure social security on old age for retired government employees only. According to Public Service Retirement Act 1974b now the retirement age of government employee of Bangladesh is 59 years $^{20}$.

Bangladesh introduced Program Implementation Plan for protecting old age health and ensures health care. This program aims to provide efficient and sustainable health service delivery and management system with skilled and special emphasis on the development of a sustained health system and improved and responsive efficient human resources ${ }^{21}$.

Recently the Parent Care Act 2013 of Bangladesh tried to ensure that the children have to take necessary steps to look after their parents for three years and provide them with maintenance. But it is not in fully functioning yet. ${ }^{22}$.

Many elderly welfare organizations work for elderly people and elderly people to get involved with the elderly welfare organization. Such as, Probin Hitoishi Kendra, Probin Hitoishi Sangha Bangladesh Association for the Aged and Institute of Geriatric Medicine (BAAIGM), Retired officers Welfare Association (Dhaka), Retired Police Officers Welfare Association (Dhaka), Service Center for Elderly People (Rajshahi), Elderly Development Initiative (Manikganj), Senakalyan Sangstha, etc.

There are initiatives taken by government and NGOs and social organizations for elderly but it is not enough to cover the whole elderly population of Bangladesh.

Elderly in traditional situation: Traditionally, the son is to take responsibility to provide food and shelter to their parents as well as take care of the other elderly members of their family. Due to their economic condition they are not able to meet the basic needs. Sometimes older people get involved in begging to meet their needs as well family needs ${ }^{14}$. 
In Bangladesh customarily gender roles are clearly defined and accepted. It is usually the men who are the main source of income while women maintain the household. In this male dominated society it is often the older men are still involved in economic activities ${ }^{23}$.

Still in Bangladesh older persons are respected and valued in the society. They have a special position in the family, often asked for advice especially during major events, like marriage, name giving ceremonies etc. In many joint families and households, they not only continue receiving care and support from the family members but also provide care to the family members such as financial help and love and care to grandchildren. No in this day in rural and urban area especially urban area both male and female are employed. In those families where parents are employed, grandparents are taking care of the family.

In Bangladesh older people are treated as an important advisor in the family as well as community. The older people resolve the family as well as community level problems. But this situation is changing for family setup and social change ${ }^{23}$.

Findings: root causes of vulnerability of elderly in Bangladesh: Available literature shows that in our society, elderly person are facing many kinds of social, mental, medical and economic problem. Because of their age, the elderly in Bangladesh is facing following challenges. Figure 2 shows the cause of vulnerability of elderly.

Due to the social context of Bangladesh, most of women in rural and slum area do not own land and other property and they are on worse situation in the old age, though the country has law to distribute assets and land to the women. Moreover, according to the Muslim Personal Law (Shariat) application act, 1937 (ACT NO. XXVI OF 1937) the wife inherits one-eight if there is child and if there be no child gets one-fourth ${ }^{24}$.

In Bangladesh traditional family patterns are breaking down which change norms and values such as respect to elderly people in the family and the community. As a result vulnerability of the elderly people is increasing. The vulnerability is in terms of food consumption, shelter, community and social attitude.

In Bangladesh, the elderly suffer from multiple health problems. Such as, weakness, tooth problem, hearing problem, vision problem, body ache, back pain, rheumatic pain and stiffness in joint, dementia, prolonged cough, breathing difficulty, asthma, palpitation, high blood pressure and micturition incompetence, which may demand long term psychosocial treatment, nursing care and hospitalization. 
Root causes of vulnerability

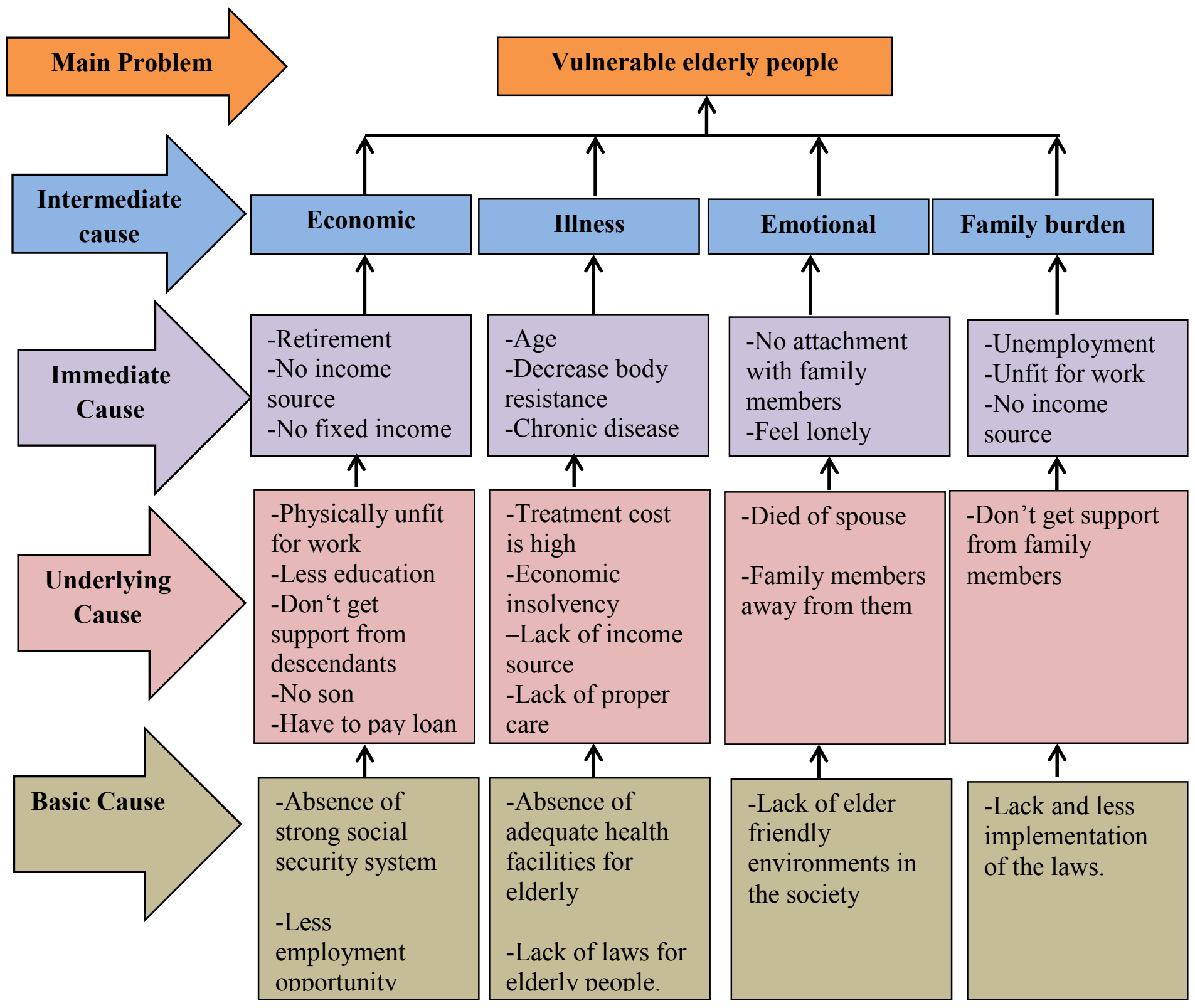

Figure 2: Root causes of vulnerability

Elderly people are sometimes abused by community and also by the family members. Due to increasing small sized family elderly people are living a corner of the house. Elderly people now are often living in isolation as other family members are busy with their own business and do not have enough time to spend with them .In this modern life children are living in cities for earning, or for education. Their parents live in separately in the rural setup, and in this busy life children are not able to visit their parents regularly. As a result parents feel lonely and isolated. 
Loneliness and anxiety are grave emotional problems encountering the older population, especially for the elderly women. Life expectancy of Bangladeshi people is 65 for male and 68 for female (Ref). In this study revealed that that the situation of older women is much worse than older men because of their longer life expectancy and extreme vulnerability due to social and economic marginalization.

Emerging issues and challenges of elderly: Taking adequate care of the elderly will be a major challenge for Bangladesh. This is mainly due to inadequate resources being allocated for the services to the elderly and no proper planning or strategic interventions for providing holistic care to them. The emerging issues of the elderly are mentioned as a 'current and upcoming challenges' in the draft National Health Policy, 2008 ${ }^{25}$. The challenges are:

Unemployment and burden: Elder persons are being considered "unemployable" because of their age and forced to stop working because of mandatory retirement ages. The ratio of work force to dependent population will show too many dependent people which will lead to a burden for the working group.

More treatment cost: Elder person facing non-communicable diseases which may need long term treatment and its cause burden more treatment cost and nursing care. The economic vulnerable people cannot afford the treatment cost to treat the older people

Considerable resources need: As the increasing size of the elderly population in Bangladesh will become a major social challenge, well planned programmes have to be undertaken and adequate resources allocated for the support, of the elderly population.

Pressure in pension scheme: With people enjoying longer lives pension schemes will have more beneficiaries who will be eligible for pensions for a longer period.

Social security scheme system will come under increasing pressure: Social security schemes will have to accommodate more people and therefore will be under pressure.

Conclusion: The root causes of vulnerably of elderly are medical, economical, emotional and social issues which are concerns not only for the individual or family, but s also a concern for the community. Increase in medical costs, pressure on social security and unemployment are main challenges of elderly facing in Bangladesh. Elderly have knowledge, experience, and wisdom. Society can use these resources of elderly in the national reconstruction. They are the asset of the nation. It is the responsibility of everyone to take care of them and utilize this asset. The elderly is the last stage of our life cycle and a reality. Everybody has to pass through this stage. So it is the responsibility of all citizens of Bangladesh to come forward for the wellbeing of our elderly. 
Recommendations: To ensure wellbeing of elderly persons following measures should be taken.

1. Dialogue with the family members of the elderly persons to ensure their wellbeing and proper care.

2. Family members, students, practitioners should be trained in elderly care.

3. The elderly themselves should be educated in self-care.

4. Aware and motivate the elderly people to involve with the elderly welfare organizations.

5. For elderly care and responsibilities should be including in text book to teach new generation to teach theirs roles and responsibility.

6. Establishment of recreation facilities for the old people,

7. To ensure good health and refresh mind of elderly people need to ensure home-based and institute-based health care centers where they receive proper nursing and care. To ensure refresh mind need to established recreation centers for them.

8. Increase NGO services such as outdoor and indoor health care.

9. Retirement age should increase to 65 years to create opportunities and they can utilize their productive years for the benefit of the society and can establish their positive image in the country.

10. Increase large scale social security programs, like, pension, old age allowance and health insurance. Government should increase outdoor service units in government hospitals and special free transport services for the elderly.

11. Implement recommendation of Vienna International Plan of Action on Aging and Political Declaration and Madrid International Plan of Action on Ageing.

12. Need to have a detailed survey providing current data on the number and conditions of the aged.

\section{Limitations of the study:}

We used qualitative tools for data collection but only qualitative findings are not sufficient for entire data analysis. For this it was needed to use quantitative data collection tools in this research.

\section{Further scope of study:}

Though we have some limitations in our study this study will also open opportunities for further research regarding elderly people such as study on indigenous people elderly people in Bangladesh.

Conflict of Interest: All authors declared no conflict of interest. 


\section{References:}

1.World Population Ageing 2013, Department of Economic and Social Affairs Population Division, United Nations • New York, 2013 Available from:

Available

from:

http://www.un.org/en/development/desa/population/publications/pdf/ageing/WorldPopulationAgeingRep ort2013.pdf

2.Bangladesh Bureau of Statistics (BBS) 2003

3. Population \& Housing Census Report 2011, Bangladesh

4. M. Nazrul Islam, Dilip C. NathA Future Journey to the Elderly Support in Bangladesh, Journal of Anthropology, Volume 2012 (2012), Article ID 752521

5.K.M. Mustafizur Rahman, Muntasir Ibn Mohsin and Ismail Tareque, Trends of Population Ageing from 1950-2050: A Comparative Study Between Bangladesh and World, Pakistan Journal of Social

Sciences, Year: 2009, Volume: 6, Issue: 1, Page No.: 6-10

6. Definition of an older or elderly person, Health statistics and information systems, WHO. Available from: http://www.who.int/healthinfo/survey/ageingdefnolder/en/

7. Unnayan Onneshan Policy Brief On Present Social Context and Elderly Population in Bangladesh. $\begin{array}{lllll}\text { Author } & \mathrm{K} & \mathrm{M} & \text { Mustafizur } & \text { Rahman. }\end{array}$ http://www.unnayan.org/reports/Policy\%20Brief\%20on\%20Elderly\%20Population.pdf

8. Social safety net - Wikipedia, the free encyclopedia

9. Abedin, S., Population aging in Bangladesh. Issues and Perspectives, Summary of the Country Paper, ESCP, Asian Popultion Studies Series, 1996, No. 145.

10. M. Taj Uddin, Md. Nazrul Islam, Md. Johurul Alam and Gias Uddin Baher, Socio-Eonomic Status of Elderly of Bangladesh: A Statistical Analysis, Research article,

11. J Shaheed Suhrawardy Med Coll, 2012;4(1):1-2, Ageing and Health : How far Bangladesh is prepared 12.Russell Kabir, Hafiz T. A. Khan, Mohammad Kabir, M. Twyeafur Rahman, Population ageing in Bangladesh and its implication on health care, European Journal of Scientific Research 9(33):34$47 \cdot$ November 2013.

13. Rahman, H., 1999. International year of the older persons and the cases of Bangladesh. Bangladesh

J. Geriatrics, 36: 144-144.

14. Rahman, A., Beggary on Aging: An Analysis (Bangoli). Dhaka University Patrica, Dhaka, 2000. Vol. 66, pp: 89.

15.Kabir M, Haque M, and Chaklader H. Mainstreaming ageing in health: Will it be possible. Paper presented in the International conference on mainstreaming ageing in health system and rural development, Dhaka, November, 2005.

16. Abedin S., Living and care arrangements of the elderly in Bangladesh. The elderly contemporary Issues: Bangladesh Association of Gerontology. 2003.

17. Roy, S. (2002) "Psychological Problems of Older People and Some Aspects of Alighting from these Problems”, Social Science Journal, Rajshahi University, Vol. 7, pp. 73-83.

18.Bangladesh Parliament, Quick link, Constitution, the constitution of the people's republic of Bangladesh,

Available from: http://www.parliament.gov.bd/index.php/en/view-all

http://bdlaws.minlaw.gov.bd/pdf_part.php?id=367

19. Ministry of Social Welfare, Government of the People's Republic of Bangladesh, 
Available from: http://www.msw.gov.bd/site/page/18350636-86ea-46fc-

8ecfdf73ed933a96/\%E0\%A6\%AC\%E0\%A7\%9F\%E0\%A6\%B8\%E0\%A7\%8D\%E0\%A6\%95-

$\% \mathrm{E} 0 \% \mathrm{~A} 6 \% \mathrm{AD} \% \mathrm{E} 0 \% \mathrm{~A} 6 \% \mathrm{BE} \% \mathrm{E} 0 \% \mathrm{~A} 6 \% \mathrm{~A} 4 \% \mathrm{E} 0 \% \mathrm{~A} 6 \% \mathrm{BE}$

20.The public servants (retirement) act, 1974, Government of the People's Republic of Bangladesh, Legislative and Parliamentary affairs division,

21. Health, Population and Nutrition Sector Development Program (HPNSDP), Planning Wing

Ministry of Health and Family Welfare, Government of the People's Republic of Bangladesh

22.Parent Care Act 2013of Bangladesh. Laws of Bangladesh, Legislative and Parliamentary Affairs Division, Bangladesh.

Available from: http:/www.ilo.org/dyn/natlex/natlex4.detail?p lang=en\&p isn=95797

23. Professor Samad Abedin, Social and Health Status of the Aged in Bangladesh, CPD, UNFPA, Paper 4, Available from: http://www.cpd.org.bd/pub_attach/unfpa4.pdf

24.Muslim Personal Law (Shariat) application act, 1937 (ACT NO. XXVI OF 1937), Laws of Bangladesh, Legislative and Parliamentary Affairs Division, Bangladesh.

Available from: http://bdlaws.minlaw.gov.bd/index.php?page=html\&language=english

25. National Health Policy, final draft 2008, Ministry of Health and Family Welfare Government of the People's Republic of Bangladesh Available from:

https:/extranet.who.int/nutrition/gina/sites/default/files/BGD $\% 202008 \% 20$ National $\% 20$ Health $\% 20$ Policy . $\mathrm{pdf}$ 